\title{
Biorefinery valorization of autohydrolysis wheat straw hemicellulose to be applied in a polymer-blend film
}

\author{
Héctor A. Ruiz*, Miguel A. Cerqueira*, Hélder D. Silva, Rosa M. Rodríguez-Jasso, \\ António A. Vicente*, José A. Teixeira \\ IBB - Institute for Biotechnology and Bioengineering, Centre of Biological Engineering, University of Minho, Campus de Gualtar, 4710-057 Braga, Portugal
}

\section{A R T I C L E I N F O}

\section{Article history:}

Received 12 September 2012

Received in revised form

10 November 2012

Accepted 10 November 2012

Available online $\mathrm{xxx}$

\section{Keywords:}

Hydrothermal process

Lignocellulosic material

Extraction

Polymeric blends films

Biorefinery concept

\begin{abstract}
A B S T R A C T
The aims of this study were the extraction of hemicellulose from wheat straw (WS) and its utilization in the reinforcement of a $\kappa$-carrageenan/locust bean gum ( $\kappa$-car/LBG) polymeric blend films (PBFs). WS hemicellulose extraction was performed under autohydrolysis process and hemicellulose extracted (HE) under optimum condition was used in PBFs. PBFs were prepared varying different proportions of HE into the $\kappa$-car/LBG film-forming solutions. Barrier properties (water vapor permeability, WVP), mechanical properties (tensile-strength, TS and elongation-at-break, EB), moisture content, opacity and thermal properties of the resulting PBFs were determined and related with the incorporation of HE. The 2-3-2 proportion (in the high ratio) of PBF ( $\kappa-\mathrm{car} / \mathrm{LBG} / \mathrm{HE}$ ) causes a slight decrease of WVP and an increase of the TS, thus resulting in an improvement of the physical properties of PBFs. HE showed to be a promising material in order to reinforce $\kappa$-car/LBG PBF and can be an alternative in the application of hemicellulose according to biorefinery concept.
\end{abstract}

(c) 2012 Elsevier Ltd. All rights reserved.

\section{Introduction}

Due to environmental considerations concerning sustainable development in the last years, the renewable resources currently attract increasing interest as raw material for industry. The term "biorefinery" of lignocellulosic materials (LCM) from forest, agricultural residues, industry or urban solid wastes is analogous to the classical petroleum refinery concept and refers to biomass conversion into fuels and chemicals with high added value as well as polymeric blend film (PBF) production through the integration of clean processes (Cherubini \& Ulgiati, 2010; Kim \& Day, 2011).

Polymer blend may be understood as the homogeneous mixture of two or more different species of polymers. The usual objective for preparing a novel blend of polymers is to capitalize the maximum possible performance of the blend without changing drastically the properties of the components (Varghese, 1998).

In recent years, studies about the utilization of LCM as new polymeric blends films are increasing due to the improvements that natural fibers and biopolymers for films and coatings (e.g. hemicellulose $O$-acetyl-galactoglucomannan, arabinoxylan) can provide, such as low density and biodegradability, excellent mechanical and

\footnotetext{
* Corresponding authors. Tel.: +351 253604 400; fax: +351 253604429 .

E-mail addresses: hector_ruiz@deb.uminho.pt (H.A. Ruiz), miguelcerqueira@deb.uminho.pt (M.A. Cerqueira), avicente@deb.uminho.pt (A.A. Vicente).
}

physical properties, besides the fact that these materials are from renewable and less expensive sources (Dogan \& McHugh, 2007; González, Santos, \& Parajó, 2011; Hartman, Albertsson, Lindblad, \& Sjoberg, 2006; Roos, Persson, Krawczyk, Zacchi, \& Stalbrand, 2009; Vicente, Cerqueira, Hilliou, \& Rocha, 2011). For these reasons, biodegradable polymers from lignocellulosic residues can be considered environmentally safe alternatives for the development of new polymeric blends (Avérous \& Le Digabel, 2006; Yu, Dean, \& Li, 2006).

Wheat straw (WS) is one of the most abundant agricultural by-products in the world and according to Food and Agriculture Organization of the United Nations (http://www.fao.org, 2011) statistics reported a world annual wheat production in 2010 of 651 million tons. WS presents many interesting characteristics and consists mainly of cellulose (30-40\%), hemicellulose (20-35\%) and lignin (15-25\%). Hemicelluloses are heteropolysaccharides made up of pentoses (xylose, arabinose), hexoses (mannose, glucose and galactose), uronic acid units and the most abundant hemicellulosic polymers are xylans. On the other hand, the hemicelluloses can be separated by various extraction and isolation methods, and then utilized in a number of ways that facilitate its biotechnology upgrade in a biorefinery concept (Gírio et al., 2010; Sedlmeyer, 2011; Mikkonen \& Tenkanen, in press). Hemicelluloses from WS have been studied after alkaline extraction (Sun, Tomkinson, Wang, \& Xiao, 2000); however, hemicellulose extraction using eco-friendly processes has received little attention. Autohydrolysis or hydrothermal processing is an environmentally 
friendly process in which LCM is pretreated with compressed hot water and used to extract hemicelluloses into the water phase. The acidic groups bounded to the hemicelluloses are released at high temperatures. These acids, mainly acetic acid and hydronium ions, which come from water autoionization, participate in the hydrolysis of the solid LCM to soluble polysaccharides; in the process of xylan polymerization this includes the conversion of xylan into high-molecular weight xylooligomers, low-molecular weight xylooligomers, xylose and dehydration of xylose into furfural. In the polymeric form they can be used as hydrogels and biodegradable barrier films for food packaging, in the oligomeric form can be used as functional food ingredients and the monomeric form can be fermented to ethanol or xylitol (Hansen \& Plackett, 2008; Ruiz, Ruzene, Silva, Quintas, et al., 2011; Ruiz, Silva, et al., 2012).

Recently, it has been shown that the mixture of polysaccharides could be used to improve physical properties of PBFs. The mixture of $\kappa$-carrageenan and locust bean gum ( $\kappa$-car/LBG) has been studied and it has been shown that their "synergistic" effects gives rise to enhanced properties that allow their application as edible films (Martins et al., 2012, in press). The incorporation of HE in this $\mathrm{K}-$ car/LBG system can be very attractive leading to the improvement of its physical properties. The aims of this work were the hemicellulose extraction using autohydrolysis process, and the application of this extracted hemicellulose under optimum condition as reinforcements for $\kappa$-car/LBG PBF. The optimization, characterization of hemicellulose extraction from autohydrolysis process and the physicochemical properties of the PBFs were also considered.

\section{Materials and methods}

\subsection{Raw material}

WS used in this study was kindly provided by a local farmer (Elvas, Portugal). The WS was cut into small pieces $(1-3 \mathrm{~cm})$ and milled using a laboratory knife mill (Cutting Mill SM 2000, Retsch, Germany). The material composition was previously analyzed by Ruiz, Ruzene, Silva, Quintas, et al. (2011), containing 37.4\% glucan, $29.4 \%$ xylan, $1.9 \%$ arabinan, $2.5 \%$ acetyl group, $26.8 \%$ total lignin, and $1.6 \%$ ash. $\kappa$-Car (Gelcarin DX5253) and LBG (Genu gum type RL-200) were supplied by FMC Biopolymer (Norway) and CP Kelco (USA), respectively. All standard chemicals used were of analytical grade. Birchwood xylan was used as a representative of the hemicellulose component and was purchased from Sigma-Aldrich (Steinheim, Germany).

\subsection{Autohydrolysis process and severity parameter effect of WS hemicellulose extraction}

The hemicellulose extraction experiments were carried out in $160 \mathrm{~mL}$ total volume stainless steel cylindrical reactors under isothermal conditions (Ruiz, Vicente, \& Teixeira, 2012). The reactor was closed, mounted vertically and then submerged in a Julabo oil bath open heating circulator (JULABO Labortechnik GmbH, Seelbach, Germany) with PID temperature control. For the extraction reactions, milled WS with a particle size distribution of $10 \%>1 \mathrm{~mm}$; $40 \%$ between 1 and $0.5 \mathrm{~mm} ; 40 \%$ between 0.5 and $0.3 \mathrm{~mm}$; and $10 \%$ to $<0.3 \mathrm{~mm}$ was mixed in an acrylic cylinder blender and suspended in the desired amount of distilled water in order to obtain a 1:10 solid/liquid mass ratio (Ruiz, Vicente, et al., 2012). The conditions of temperature and time used in each experiment are shown in Table 1 . The effectiveness of autohydrolysis process was evaluated using the severity factor in order to summarize in one variable the main autohydrolysis parameters effects (reaction time and temperature). The severity values $\log \left(R_{0}\right)$ were calculated as defined by Overend and Chornet (1987), as shown in Eq. (1), where $t$ is the reaction time ( $\mathrm{min}), T$ is the process temperature $\left({ }^{\circ} \mathrm{C}\right), 100$ is the temperature of reference and 14.74 is an empirical parameter related with activation energy, assuming pseudo-first order kinetics.

$\log \left(R_{0}\right)=\int_{0}^{t} \exp \left[\frac{T-100}{14.75}\right] d t$

At the end of the desired reaction time, the reactor was removed from oil bath and cooled down by soaking in an ice-water bath for $5 \mathrm{~min}$. The $\log \left(R_{0}\right)$ values were calculated from the constant set temperatures and residence times during heating at constant temperature, the heating up and cooling were not taken into consideration. The solid and liquid were separated by filtration using vacuum pump equipment (Gast Manufacturing, MI, USA). Three volumes of $95 \%$ ethanol absolute (99.8\%, Carlo Erba, France) were added to the filtrate in order to precipitate high-molecular weight hemicellulose. The liquid phase was separated from the precipitated hemicellulose by centrifugation $\left(7885 \times \mathrm{g}, 10 \mathrm{~min}, 4^{\circ} \mathrm{C}\right)$. Distilled water was added to the precipitated hemicellulose in a proportion of 1:2 (precipitated hemicellulose:water) and the hemicellulose extracted (HE) was lyophilized and kept in a dry place until further use (Cerqueira et al., 2009). Hemicellulose extraction yield reported as a percentage (\% $\mathrm{HEY}$ ) was calculated dividing the mass obtained after ethanol precipitation by the initial mass of wheat straw.

\subsection{Autohydrolysis experimental design and optimization of hemicellulose extraction}

For optimization of the hemicellulose extraction yield (\% HEY) a response surface methodology (RSM) was applied. Table 1 shows the independent variables of temperature $\left(X_{1},{ }^{\circ} \mathrm{C}\right)$ and time $\left(X_{2}\right.$, $\mathrm{min}$ ) for three variation levels on the extraction of hemicellulose. The total number of observations required for two independent variables $(N)$ was calculated using the following equation:

$N=2^{K}+2 \cdot K+1$

where $K$ is the number of independent variables. $N$ is found to be 8 with four replicates at the center point leading to a total number of 12 experiments for the evaluation of the extraction process. Four assays at the center point of the design were carried out to estimate the random error needed for the analysis of variance. The values of the independent variables were normalized from -1 to +1 using Eq. (3) to provide the comparison of the coefficients and visualization of the individual independent variables on the response.

$X_{n}=2 \frac{X-\bar{X}}{X_{\max }-X_{\min }}$

where $X$ is the absolute value of the independent variable concerned $\bar{X}$ is the average value of the variable and $X_{\max }$ and $X_{\min }$ are its maximum and minimum value, respectively. The secondorder polynomial was calculated with MATLAB Version 7.6.0, R2008a software (MathWorks, Inc., Natick, MA, USA) to estimate the response of the dependent variables. The mathematical model corresponding to the experimental design is:

$Y_{i}=\beta_{0}+\sum_{i=1}^{3} \beta_{i} x_{i}+\sum_{i=1}^{3} \beta_{i i} x_{i}^{2}+\sum_{i=2}^{2} \sum_{j=i+1}^{3} \beta_{i j} x_{i} x_{j}$

where $Y_{i}$ is the predicted value, $x_{i}$ and $x_{j}$ are the normalized values of the factors (time, temperature), $\beta_{0}$ is a constant coefficient, $\beta_{i}$ are the linear coefficients, $\beta_{i j}(i$ and $j$ ) are the interaction coefficients and $\beta_{i i}$ are the quadratic coefficients. The quality of the fit of the polynomial model equation was evaluated by the coefficient of determination $R^{2}$ and the statistical significance was evaluated by 
Table 1

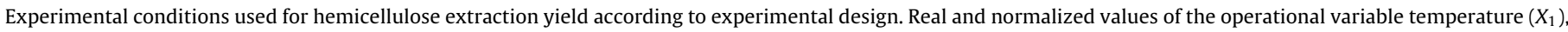
times $\left(X_{2}\right)$, and results obtained for the responses on hemicellulose extraction yield (\% HEY) response, $\mathrm{pH}$ and $\log \left(R_{0}\right)$ severity values.

\begin{tabular}{|c|c|c|c|c|c|c|c|c|}
\hline \multirow[t]{2}{*}{ Assay } & \multicolumn{4}{|c|}{ Variables } & \multicolumn{4}{|c|}{ Responses } \\
\hline & $X_{1}$ & & $X_{2}$ & & $Y_{(\% \mathrm{HEY})}{ }^{\mathrm{a}}$ & $Y_{(\% \mathrm{HEY})}{ }^{\mathrm{b}}$ & $\mathrm{pH}^{\mathrm{c}}$ & $\log \left(R_{0}\right)$ \\
\hline 1 & 160 & $(-1)$ & 10 & $(-1)$ & 5.7 & 3.05 & 5.2 & 2.77 \\
\hline 2 & 160 & $(-1)$ & 50 & (1) & 10.3 & 8.80 & 4.6 & 3.47 \\
\hline 3 & 160 & $(-1)$ & 30 & $(0)$ & 7.8 & 11.94 & 4.8 & 3.24 \\
\hline 4 & 200 & (1) & 10 & $(-1)$ & 8.3 & 8.82 & 4.95 & 3.94 \\
\hline 5 & 200 & (1) & 50 & (1) & 2.99 & 4.66 & 3.45 & 4.64 \\
\hline 6 & 200 & (1) & 30 & $(0)$ & 14.96 & 12.65 & 4.25 & 4.42 \\
\hline 7 & 180 & $(0)$ & 10 & $(-1)$ & 11.7 & 13.82 & 5.1 & 3.36 \\
\hline 8 & 180 & $(0)$ & 50 & (1) & 14.8 & 14.61 & 4.25 & 4.05 \\
\hline 9 & 180 & $(0)$ & 30 & $(0)$ & 21.55 & 20.22 & 4.45 & 3.83 \\
\hline 10 & 180 & $(0)$ & 30 & $(0)$ & 19.69 & 20.22 & 4.5 & 3.83 \\
\hline 11 & 180 & $(0)$ & 30 & $(0)$ & 23.47 & 20.22 & 4.47 & 3.83 \\
\hline 12 & 180 & $(0)$ & 30 & $(0)$ & 18.14 & 20.22 & 4.5 & 3.83 \\
\hline
\end{tabular}

a Experimental value.

b Model predicted value.

c Final $\mathrm{pH}$ in the liquid phase.

the Fisher's F-test for analysis of variance (ANOVA) with a 95\% confidence level. The effect of each independent variable and also their interaction effects were determined. The experimental design package STATISTICA ${ }^{\mathrm{TM}}$ v 7.0 (Statsoft $^{\circledR}$, Tulsa, OK, USA) was the software used for data analysis.

\subsection{Characterization of autohydrolysis extracted hemicellulose}

\subsubsection{Acid hydrolysis of autohydrolysis extracted hemicellulose} for determination of chemical composition

To determine the main sugar component, HE was hydrolyzed according to Akpinar, Erdogan, and Bostanci (2009) with a slight modification. In order to compare the hydrolysis profiles of HE, a commercial birchwood xylan was used as reference material. Firstly, $20 \mathrm{mg}$ of $\mathrm{HE}$ was suspended in $5 \mathrm{~mL}$ of $0.25 \mathrm{M} \mathrm{H}_{2} \mathrm{SO}_{4}$, and this suspension was incubated in a boiling water bath for $3 \mathrm{~h}$. The resulting supernatant was filtered through a $0.2 \mu \mathrm{m}$ sterile membrane filter. The reaction products (xylose, glucose and arabinose) were quantified by HPLC in a Jasco 880-PU intelligent pump (Tokyo, Japan) chromatograph equipped with a refractive index detector and a Metacarb $87 \mathrm{H}(300 \mathrm{~mm} \times 7.8 \mathrm{~mm}$, Varian, USA) column. Chromatographic separation was performed under the following conditions: mobile phase $0.005 \mathrm{M} \mathrm{H}_{2} \mathrm{SO}_{4}$, flow rate $0.7 \mathrm{~mL} / \mathrm{min}$, and column temperature $60^{\circ} \mathrm{C}$ and sample volume injection $20 \mu \mathrm{L}$.

\subsubsection{Fourier-transform infrared spectroscopy}

Fourier-transform infrared (FTIR) spectra of HE and xylan birchwood were measured on a Perkin-Elmer 16 PC spectrometer (Perkin-Elmer, Boston, USA) using 16 scans and frequency range of $400-4000 \mathrm{~cm}^{-1}$. Signal averages were obtained at a resolution of $4 \mathrm{~cm}^{-1}$. For FTIR measurement, the polysaccharide was ground with spectroscopic grade potassium bromide $(\mathrm{KBr})$ powder and then pressed into $1 \mathrm{~mm}$ pellets. The FTIR spectra of the films were recorded using Attenuated Total Reflectance mode (ATR). The vibration transition frequencies of each spectrum were baseline corrected and the absorbance was normalized between 0 and 1 .

\subsection{Preparation of polymer blend films}

PBFs were prepared using the method described by Martins et al. (in press). To prepare $\kappa$-car/LBG polymeric matrix, 0.40 and $0.60 \%$ $(\mathrm{w} / \mathrm{w})$ of $\kappa$-car and LBG, respectively, was suspended in $100 \mathrm{~mL}$ of distilled water under agitation $1 \mathrm{~h}$ at $25^{\circ} \mathrm{C}$. Then the polymeric blend film solution was homogenized at $70^{\circ} \mathrm{C}$ and stirred during $30 \mathrm{~min}$ in presence of $0.30 \%(\mathrm{w} / \mathrm{w})$ glycerol (plasticizer) until a homogeneous solution was obtained. To prepare $\kappa$-car/LBG PBFs,
Table 2

Proportions of $\kappa$-car/LBG/HE present in the polymeric blend film.

\begin{tabular}{llll}
\hline & \multicolumn{2}{l}{ Polymeric blend film } & \\
\cline { 2 - 4 } & $\mathrm{I}^{\mathrm{a}}$ & $\mathrm{II}^{\mathrm{a}}$ & $\mathrm{III}^{\mathrm{a}}$ \\
\hline K-Car & 2 & 2 & 2 \\
LBG & 3 & 3 & 3 \\
HE & 0 & 1 & 2 \\
\hline
\end{tabular}

a Glycerol (plasticizer).

HE was added to the polymeric blend solution in different proportions, as showed in Table 2 . The resulting blend film forming solutions were then degassed under vacuum to remove air bubbles and dissolved air as much as possible. Then, $28 \mathrm{~mL}$ of the filmforming solution was cast into polystyrene Petri dishes, and dried at $35^{\circ} \mathrm{C}$ during $16 \mathrm{~h}$. PBFs were conditioned at $54 \pm 1 \%$ relative humidity $(\mathrm{RH})$ and $20 \pm 1^{\circ} \mathrm{C}$ by placing them in a desiccator containing a saturated solution of $\mathrm{Mg}\left(\mathrm{NO}_{3}\right)_{2} \cdot 6 \mathrm{H}_{2} \mathrm{O}$ until further use.

\subsection{Polymer blend film characterization}

\subsubsection{Fourier-transform infrared spectroscopy of the PBFs}

The FTIR spectra characterization of polymer-blend films was analyzed as described above (see Section 2.4.2).

\subsubsection{Thickness}

A digital micrometer (No. 293-5, Mitutoyo, Japan) was used to measure film thickness. Five thickness measurements were randomly taken on each PBF sample and the average was used to calculate water vapor permeability and tensile strength (Casariego et al., 2009).

\subsubsection{Water vapor permeability (WVP)}

WVP was determined gravimetrically using the ASTM E96-92 method described by Casariego et al. (2009). Three samples were cut from each PBF. Each sample was sealed on a permeation cell (cup containing distilled water at $100 \% \mathrm{RH} ; 2.337 \times 10^{3}$ Pa vapor pressure at $20^{\circ} \mathrm{C}$ ), and placed in a desiccator containing silica gel $\left(0 \% \mathrm{RH} ; 20^{\circ} \mathrm{C}\right)$. The water transferred through the test PBF was determined from cup weight loss over time. The cups were weighed with a $0.1 \mathrm{mg}$ precision at $2 \mathrm{~h}$ intervals. The steady state of weight loss was reached after $10 \mathrm{~h}$.

\subsubsection{Moisture content}

The moisture content was determined gravimetrically measuring weight loss of $\mathrm{PBF}$ (of about $20 \mathrm{mg}$ ) at $105^{\circ} \mathrm{C}$ in an oven with 
forced air circulation for $24 \mathrm{~h}$. All the experiments were performed in triplicate. Moisture content of PBF was calculated and expressed in \% on a dry weight basis (Casariego et al., 2009).

\subsubsection{Tensile strength and elongation-at-break}

Tensile strength (TS) and elongation-at-break (EB) were determined with an Instron Universal Testing Machine (Model 4500, Instron Corporation) using ASTM Standard Method D 882-91. Film specimens ( $50 \mathrm{~mm} \times 20 \mathrm{~mm}$ strips) were cut from each preconditioned (54\% RH) film and placed between the tensile grips. The initial grip separation and crosshead speed were set to $30 \mathrm{~mm}$ and $5 \mathrm{~mm} \mathrm{~min}^{-1}$, respectively. Five samples for each type of PBF were replicated (Casariego et al., 2009).

\subsubsection{Opacity}

The opacity of the samples was determined according to the Hunterlab method, as the relationship between the opacity of each sample on a black standard and the opacity of each sample on a white standard. For each type of PBF, optical measurements were performed six times (Casariego et al., 2009).

\subsubsection{Thermal analysis of the polymeric blend film}

Thermogravimetric analysis (TGA) and differential scanning calorimetry (DSC) of the PBFs was performed using a Shimadzu TGA-50 and DSC-50 equipment (Shimadzu Corporation, Kyoto, Japan), respectively, with thermal software TASYS. Samples were weighed (approximately $10-15 \mathrm{mg}$ ) in aluminum sample pans. The experiments were conducted, under $\mathrm{N}_{2}$ atmosphere, at a heating rate of $10^{\circ} \mathrm{C} / \mathrm{min}$ over a temperature range of $20-600^{\circ} \mathrm{C}$. An empty pan was used as a reference (Cerqueira et al., 2011).

\subsubsection{Statistical analysis}

The statistical analysis was carried out using single-factor analysis of variance (ANOVA), while multiple comparison tests were used to determine the statistical significance with a 95\% confidence level. For the data analyses, MATLAB software was used.

\section{Results and discussion}

\subsection{Effect of autohydrolysis on hemicellulose extraction}

Table 1 shows the values of hemicellulose extraction yield. The degree of solubilization of hemicellulose increased for higher heating temperatures and ranged between 18.14 and $23.47 \%$ at $180^{\circ} \mathrm{C}$ for $30 \mathrm{~min}\left(\log R_{0}=3.83\right)$, decreasing to $2.99 \%$ for a heating temperature of $200^{\circ} \mathrm{C}$ for $50 \mathrm{~min}\left(\log R_{0}=4.64\right)$, probably due to the degradation of hemicellulose into furfural and other derivatives (Ruiz, Ruzene, Silva, Quintas, et al., 2011). Yoshida, Tsubaki, Teramoto, and Azuma (2010) showed a similar effect on the extraction of carbohydrates from corn starch using microwave-assisted extraction. Recently, Ruiz, Ruzene, Silva, Quintas, et al. (2011) reported the effect of process severity (temperature, time) and particle size on the composition of monosaccharides (xylose, glucose and arabinose) and the formation of its degradation products (hydroxymethylfurfural (HMF) and furfural) from WS hemicellulose, showing that glucose and xylose are degraded into HMF and furfural for higher severity treatment $\left(\log R_{0}=4.72\right)$. Overall, the behavior of xylose solubilization and the formation of its degradation products strongly correspond with hemicellulose extraction yield showed in this study. Table 1 shows that $\mathrm{pH}$ values of the liquors decrease with the severity of the process, which is explained by the increase of the acetic acid concentration. Moreover, hydronium ions are generated by the autoionization of water leads to the acidification of the liquor (Carvalheiro, Silva-Fernandes, Duarte, \& Gírio, 2009).
Table 3

Analysis of variance (ANOVA) for hemicellulose extraction yield $Y_{(\mathrm{HEY})}$ model as a function of temperature $\left(x_{1}\right)$ and time $\left(x_{2}\right)$.

\begin{tabular}{lrrrrr}
\hline Source & $\begin{array}{l}\text { Sum of } \\
\text { squares }\end{array}$ & d.f & $\begin{array}{l}\text { Mean } \\
\text { square }\end{array}$ & $F$-Value & $p$-Value \\
\hline Model & 415.87 & 5 & 83.17 & 8.95 & $0.0094^{*}$ \\
$x_{1}$ & 1.00 & 1 & 1.00 & 0.10 & 0.7539 \\
$x_{2}$ & 0.95 & 1 & 0.95 & 0.10 & 0.7597 \\
$x_{1} x_{2}$ & 24.55 & 1 & 24.55 & 2.64 & 0.1501 \\
$x_{1}^{2}$ & 165.58 & 1 & 156.58 & 17.82 & $0.0055^{*}$ \\
$x_{2}^{2}$ & 96.32 & 1 & 96.32 & 10.36 & $0.0181^{*}$ \\
Error & 55.75 & 6 & 9.29 & & \\
Total & 417.61 & 11 & & & \\
\hline
\end{tabular}

d.f., degree of freedom.

Significant.

On the other hand, it is known that when hemicellulose is subjected to autohydrolysis under specific operational conditions, xylooligosaccharides (XOS) are the major formation products. According to Boussarsar, Rogé, and Mathlouthi (2009), the soluble fraction shows the presence of xylan oligomers and polymers with large distribution of degree of polymerization (DP). Ruiz, Ruzene, Silva, Macieira da Silva, et al. (2011) reported that XOS represented $78 \%$ of the sum of sugars solubilized in the autohydrolysis liquid phase generated by the hemicellulose fraction hydrolysis. Makishima et al. (2009) used a continuous flow type autohydrolysis reactor for hemicellulose fraction from corncob and reported that during the purification of solubilized fraction, higher-XOS were recovered as the precipitate, presenting a DP ranging from 11 to 21. Garrote, Domínguez, and Parajó (2002), proposed a reaction model of xylan formation under autohydrolysis conditions, in which the ratio of the higher-XOS decreased with reaction time and the concentration of monomer sugars such as xylose increased.

\subsection{Statistical analysis and optimization of hemicellulose extraction}

Table 1 shows the process variables, experimental data and the values predicted by the model. The second-order polynomial model in terms of normalized values (Table 1) expressed in Eq. (5) represent the hemicellulose extraction yield, $Y_{(\% \mathrm{HEY})}$, as a function of temperature $\left(x_{1}\right)$ and time $\left(x_{2}\right)$, respectively.

$Y_{(\% \mathrm{HEY})}=20.22-7.88 x_{1}^{2}-6.01 x_{2}^{2}$

The ANOVA results listed in Table 3 revealed that second-order polynomial model was found to be adequate for prediction of hemicellulose extraction yield response within the range of experimental variables. The determination coefficient of the second-order polynomial model was $R^{2}=0.8817$, indicating that $11.83 \%$ of the total variations were not explained by the model. As shown in Table 3, the model F-value of 8.95 is high compared to the tabu$\operatorname{lar} F_{5,6}$ value of 4.39 indicating that the model was significant. The statistical analysis revealed that, the autohydrolysis variables had a significant influence on the hemicellulose extraction yield.

As can be deduced from Fig. 1, the Pareto chart shows the effects and significance of the variables, $x_{1}^{2}, x_{2}^{2}$, on hemicellulose extraction yield with $p$-value under a significance level of $\alpha=0.05$. The other terms were not significant $(p>0.05)$. The negative sign shows that the hemicellulose extraction yield decreases as these variables increase. Zou, Chen, Yang, and Liu (2011) reported a similar effect of time on the extraction of polysaccharides using an ultrasonic process.

Three dimensional response surface of the second-order polynomial of Eq. (5) was plotted in order to obtain the optimum point in the hemicellulose extraction yield (Fig. 2). Hemicellulose extraction yield was estimated to be $20.22 \%$ at the optimum point 


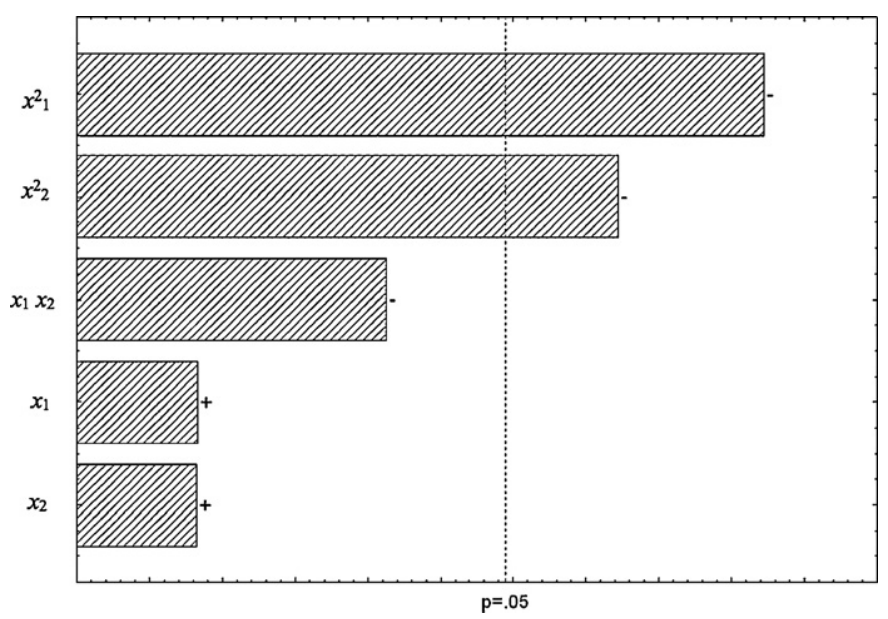

Fig. 1. Pareto chart for standardized effects on hemicellulose extraction yield: temperature $\left(x_{1}\right)$; time $\left(x_{2}\right)$.

(temperature; $180.42^{\circ} \mathrm{C}$, time; $30.56 \mathrm{~min}$ ). This optimum point was confirmed using the Hessian matrix analytical method, evaluating the values of the second order partial derivatives from second-order polynomial. The HE obtained in the optimum point was used as material in the reinforcement of $\kappa$-car/LBG matrix blend.

\subsection{Autohydrolysis extracted hemicellulose characterization}

\subsubsection{Characterization of sugars from extracted hemicellulose}

The chemical compositions (monosaccharides) of the extracted hemicellulose and commercial birchwood xylan are listed in Table 4. The chemical composition was performed after acid hydrolysis. Xylose is the most abundant sugar in the HE after the autohydrolysis treatment at $180^{\circ} \mathrm{C}$ for $30 \mathrm{~min}$, indicating the presence of a xylan as the main polysaccharide. Meanwhile, arabinose and glucose are presented in small amounts for HE. Birchwood xylan, which contains $>90 \%$ of sugars in the polysaccharides form of xylose, was confirmed after acid hydrolysis. HE and commercial birchwood xylan were found to be slightly similar, being both predominantly composed by xylose.

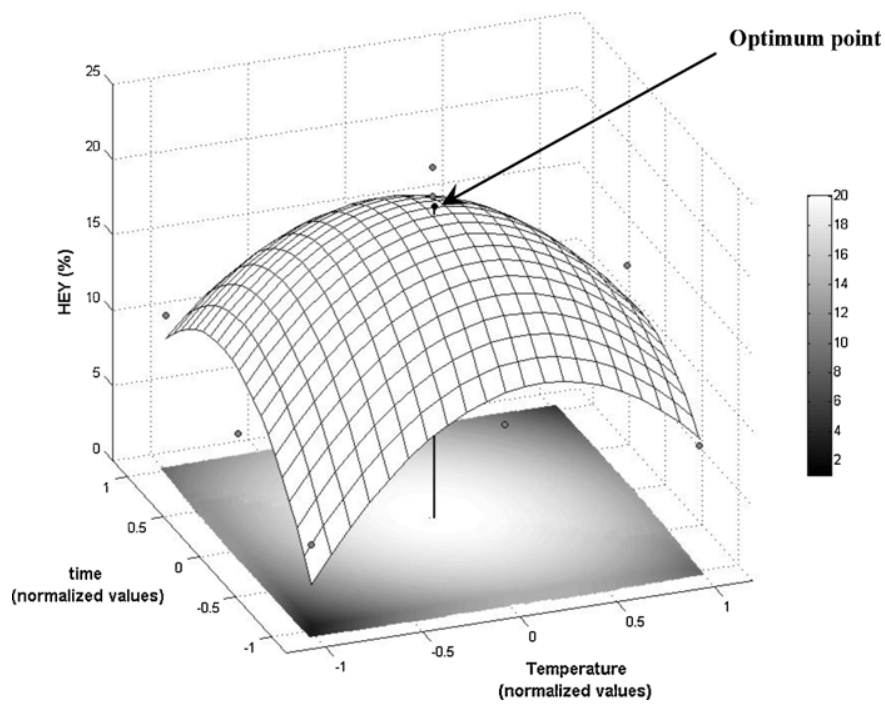

Fig. 2. Response surface and contour plot showing the effects of temperature $\left(x_{1}\right)$ and time $\left(x_{2}\right)$ on the hemicellulose extraction yield. (I ) Optimum point; ( $O$ ) evaluated experimental conditions.
Table 4

Sugar composition of autohydrolysis extracted hemicellulose under optimal conditions and birchwood xylan.

\begin{tabular}{llll}
\hline & \multicolumn{2}{l}{ Neutral sugar composition (mol\%) } \\
\cline { 2 - 4 } & Xylose & Arabinose & Glucose \\
\hline HE & 82.24 & 15.07 & 2.67 \\
Birchwood xylan & 99.48 & n.d. & 0.51 \\
\hline
\end{tabular}

Percentages are expressed as molar percentage of total monosaccharide content in the sample; n.d.: not detected.

\subsubsection{Fourier-transform infrared spectroscopy}

Infrared spectroscopy is an effective way to identify the presence of certain functional groups in a molecule. Also, one can use the unique collection of absorption bands to confirm the identity of a pure compound or to detect the presence of specific impurities. The HE infrared spectra and birchwood xylan (Fig. 3) showed the typical signal pattern expected for hemicellulose fractions. The broad absorption band at $3405 \mathrm{~cm}^{-1}$ is attributed to hydroxyl groups that normally occur as a result of the association between the polymers being its intensity influenced by the sample concentration (Sun, Sun, Fowler, \& Baird, 2005). In addition, a band at $2920 \mathrm{~cm}^{-1}$ was detected and is indicative of $\mathrm{C}-\mathrm{H}$ stretching vibrations due to $\mathrm{CH}_{2}$ and $\mathrm{CH}_{3}$ groups; also, the signal at $1375 \mathrm{~cm}^{-1}$ is due to the $\mathrm{C}-\mathrm{H}$ bending vibration present in cellulose and hemicelluloses chemical structures (Peng et al., 2009). The sharp absorption band near to $1613 \mathrm{~cm}^{-1}$ is principally attributed to the absorbed water in xylantype polysaccharides (Oliveira et al., 2010; Sun et al., 2000). The prominent band at $1043 \mathrm{~cm}^{-1}$ is the wavenumber characteristic for typical xylans, assigned to the $\mathrm{C}-\mathrm{O}$ and $\mathrm{C}-\mathrm{C}$ stretching and the glycosidic linkage contributions. Moreover a sharp band at $890 \mathrm{~cm}^{-1}$, corresponding to the C1 group frequency or ring frequency, is attributed to $\beta$-glycosidic linkages $(1 \rightarrow 4)$ between xylose units in hemicelluloses (Sun et al., 2000, 2005). Low-intensity

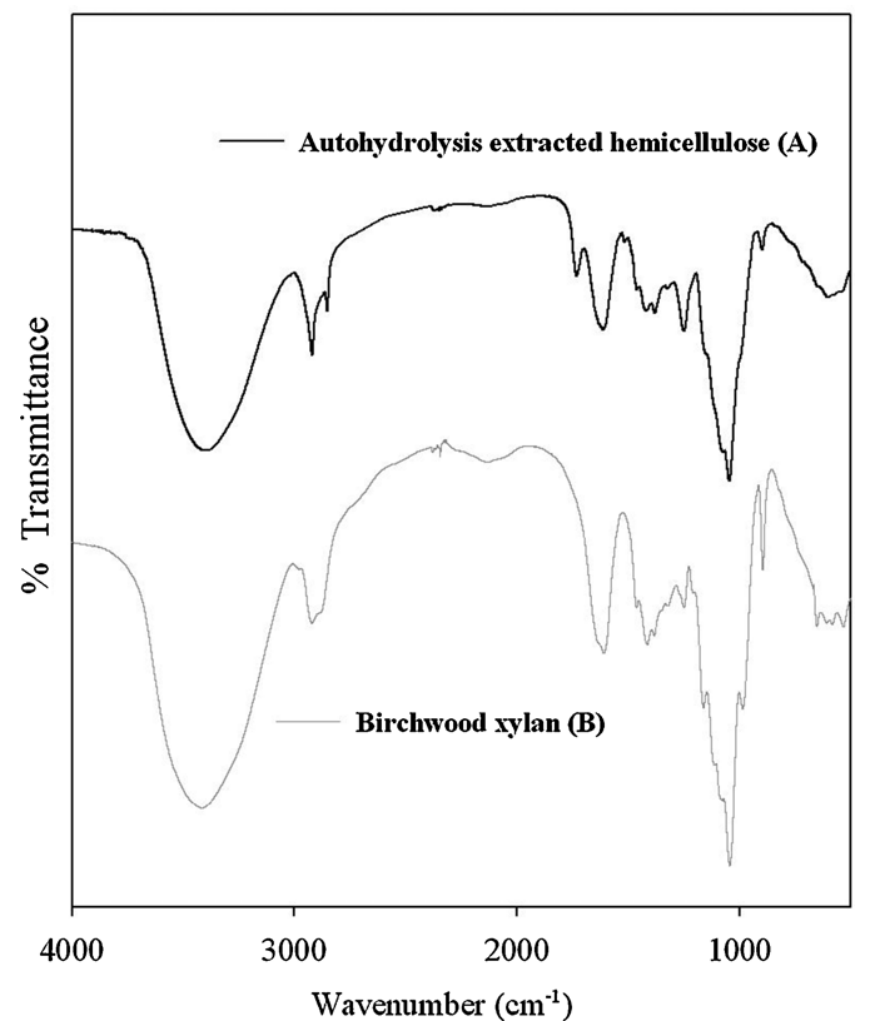

Fig. 3. FTIR spectra of extracted hemicellulose obtained by autohydrolysis at $180^{\circ} \mathrm{C}$ for $30 \mathrm{~min}\left(\log R_{0}=3.83\right.$ ) (A) and birchwood xylan (B). 
Table 5

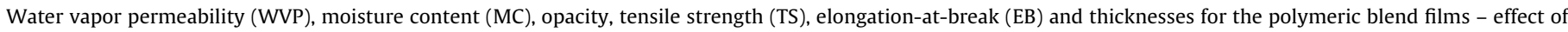
incorporation of HE.

\begin{tabular}{|c|c|c|c|c|c|c|}
\hline $\begin{array}{l}\text { Polymeric blend } \\
\text { film (PBF) }\end{array}$ & $\operatorname{WVP}\left(10^{11} \mathrm{~g}(\mathrm{~m} \mathrm{sPa})^{-1}\right)$ & $\mathrm{MC}(\%)^{\mathrm{a}}$ & Opacity (\%) & TS (MPa) & $\mathrm{EB}(\%)$ & Thicknesses (mm) \\
\hline I & $6.29 \pm 0.02$ & $24.08 \pm 1.96$ & $5.36 \pm 0.07^{*}$ & $16.49 \pm 0.30$ & $24.29 \pm 1.13$ & $0.048 \pm 0.001^{*}$ \\
\hline II & $7.01 \pm 0.26$ & $21.71 \pm 1.81$ & $9.77 \pm 0.14^{*}$ & $17.54 \pm 0.80$ & $24.15 \pm 0.90$ & $0.056 \pm 0.001$ \\
\hline III & $6.19 \pm 0.12^{*}$ & $21.21 \pm 0.58$ & $13.48 \pm 0.35^{*}$ & $19.71 \pm 0.16^{*}$ & $24.95 \pm 0.33$ & $0.053 \pm 0.002$ \\
\hline
\end{tabular}

a Dry weight basis.

* Represent means in the same column that are statistically significant different $(p<0.05)$.

shoulders at 1161 and $983 \mathrm{~cm}^{-1}$ were only detected in the birchwood fraction showing the association with arabinosyl side chains (Sun et al., 2005). On the contrary, extracted hemicellulose showed a signal at $1733 \mathrm{~cm}^{-1}$ which implies that the hemicellulosic fraction, solubilized during the water treatment, contains small amounts of acetyl, uronic, and ester groups or the ester bonds of the carboxylic groups of ferulic and/or $p$-coumaric acids (Peng et al., 2009). Hence, the band near $1613 \mathrm{~cm}^{-1}$ can also be in part attributed to the carbonyl stretching of the carboxylic (nonesterified) group. Furthermore, the weaker absorbance's at 1507 and $831 \mathrm{~cm}^{-1}$ observed in this fraction are originated from aromatic skeletal vibrations in associated lignin, indicating that $\mathrm{HE}$ was contaminated with amounts of bound lignin (Sun et al., 2005). Montané, Nabarlatz, Martorell, Torné-Fernandez, and Fierro (2006) reported that the XOS produced by the autohydrolysis contain lignin-derived phenolics impurities. Liu, Fatehi, Sadehi, and Ni (2012) showed some impurities as lignin in the hemicellulose extracted.

\subsection{Polymer blend films characterization}

\subsubsection{Fourier-transform infrared spectroscopy of the polymer blend films}

FTIR spectroscopy was used to characterize different polysaccharides and their structures (e.g. edible films). When chemical groups interact at the molecular level, changes in FTIR spectra such as the shifting of absorption bands could happen. These changes can be an indication of good miscibility of polymers, and can be useful to evaluate the interaction between HE and $\kappa$-car/LBG PBFs (Xu, Li, Kennedy, Xie, \& Huang, 2007).

Fig. 4 shows the FTIR spectra of with increasing HE proportions. The broad band ranging between 3500 and $3100 \mathrm{~cm}^{-1}$ was attributed to $\mathrm{O}-\mathrm{H}$ stretching vibration formed by the hydroxyl group being the broad band around $2800-3000 \mathrm{~cm}^{-1}$ attributed to $\mathrm{C}-\mathrm{H}$ stretching vibration (Cerqueira et al., 2011). FTIR spectra of the samples also shows a band in the region of $750-1300 \mathrm{~cm}^{-1}$ that is characteristic of the carbohydrate region. These wavenumbers are within the so-called fingerprint region, where the bands are specific for each polysaccharide, allowing its possible detection (Şen \& Erboz, 2010). Martins et al. (2012) showed that the mixture of the two polysaccharides lead to the presence of the peaks characteristic of the $\kappa$-carrageenan (at $1220 \mathrm{~cm}^{-1}$ corresponding to the ester sulfate groups, a peak at $922 \mathrm{~cm}^{-1}$ attributed to the 3,6 -anhydrogalactose group, a peak at $846 \mathrm{~cm}^{-1}$ corresponding to galactose-4-sulfphate and a peak at $805 \mathrm{~cm}^{-1}$ corresponding to 3,6anydro-D-galactose-2-sulfate) and from the Locust Bean Gum (LBG) (that shows absorption bands at $817 \mathrm{~cm}^{-1}$ and $873 \mathrm{~cm}^{-1}$ indicating the presence of $\alpha$-linked D-galactopyranose units and $\beta$-linked D-mannopyranose units). It has been shown that the interaction between the two polysaccharides lead to changes in the peak position of their main groups (Martins et al., 2012).

In the spectra of the PBFs it is possible to observe shifts in characteristic peaks when the HE is added, such as those corresponding to $\mathrm{C}-\mathrm{H}$ stretching vibrations that shift from 2934 to 2930 and $2923 \mathrm{~cm}^{-1}$ and from 2891 to 2896 and $2902 \mathrm{~cm}^{-1}$ for the polymeric blend films II and III, respectively. It is also clearer the presence of a new peak in the PBFs when the HE is added. The peak at $1733 \mathrm{~cm}^{-1}$ corresponds to the presence of the hemicellulosic fraction in the HE samples, as explained before. The shifts of the peaks at 1184 to 1190 and $1195 \mathrm{~cm}^{-1}$ and the shift from 973 to 952 and $953 \mathrm{~cm}^{-1}$ when HE is added to the polymeric films II and III, respectively, indicates a change in the polysaccharides fingerprint region, that can be related with the composition of the HE.

The modifications in the stretching frequencies of some groups that are involved in interactions can be a indication of the interaction between the films' constituents and the added HE, being the change (shift) of peak position dependent of the strength of the interaction (Wanchoo \& Sharma, 2003). These interactions may lead to changes in PBFs properties (e.g. transport and mechanical properties).

\subsubsection{Water vapor permeability}

The utilization of PBFs as packaging often implies the need to block, or at least retard, moisture transfer between the food and the surrounding atmosphere. The water vapor permeability (WVP) depends on many factors, such as the integrity of the PBF, the

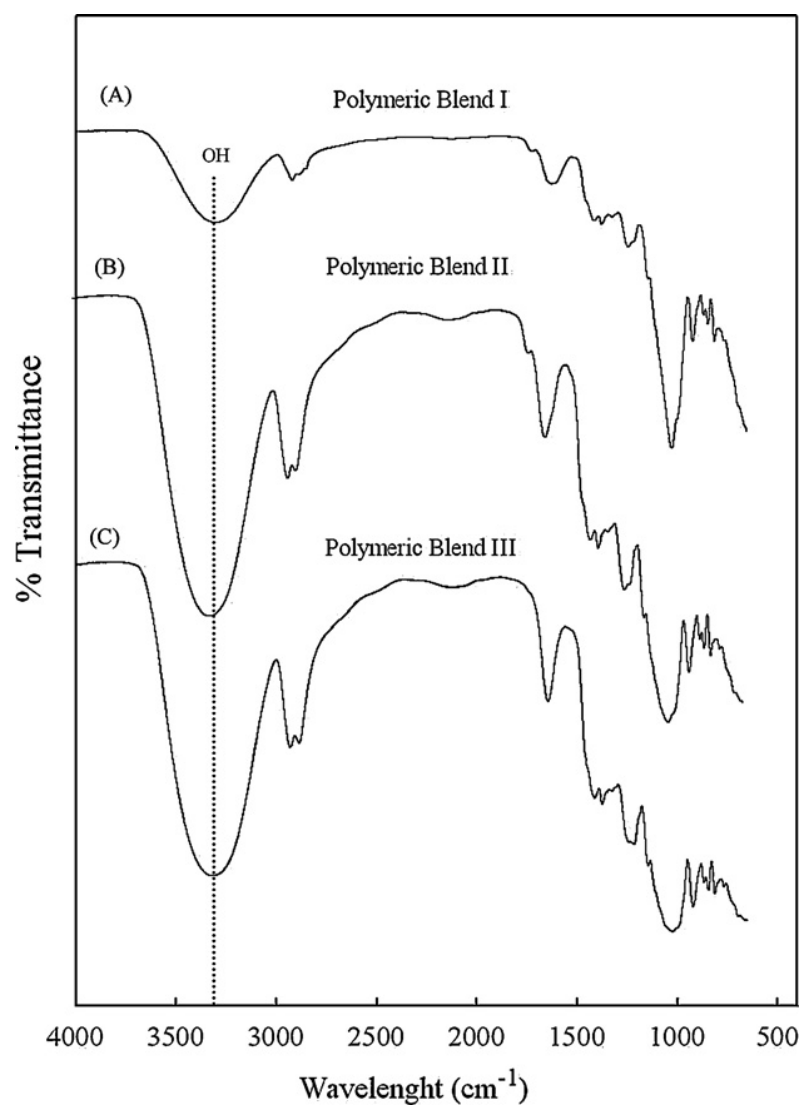

Fig. 4. FTIR spectra of the polymeric blend films: polymer blend film I (A); polymer blend film II (B); polymer blend film III (C). 
hydrophilic-hydrophobic ratio, the ratio between crystalline and amorphous zones, the polymeric chain mobility and the tortuosity of the film matrix (Miller \& Krochta, 1997; Souza, Cerqueira, Teixeira, \& Vicente, 2010). The increase of HE proportion in the polymeric matrix of $\kappa$-car/LBG films results in increases of the values of thickness (Table 5).

Table 5 reports the WVP values of $\kappa$-car/LBG films with different HE proportions. The PBF in a proportion of $\kappa$-car:LBG:HE 2-3-2 leads to significantly $(p<0.05)$ lower WVP values when compared with the other films formulation. The presence of HE in the film (in the high proportion) structure decreases the water vapor permeability of the films, this can be related with the increase of the matrix crystallinity, this is possibly due to the increased tortuosity of the film structure. The HE dispersion in the film may have increased in the tortuosity that leads to a lower diffusion of water molecules through the matrix (Martins et al., in press; SanchezGarcia, Gimenez, \& Lagaron, 2008). Moisture content of the films confirmed this possibility (Table 5 ), once no statistically significant differences were observed for the different HE proportions. Being so, the HE does not change the hydrophilicity of the PBF, but in some way affects the tortuosity of the matrix, changing the available pathways for water molecules to diffuse through the matrix. Martins et al. (in press) obtained similar results with the incorporation of Cloisite $30 \mathrm{~B}$ in the same PBF proportion. The presence of $1 \%$ of Cloisite $30 \mathrm{~B}$ (which is an amount close to the one used in the present work) in $\kappa$-car/LBG polymer blend films leads to a decrease of $6 \%$ in the WVP values, in the same range of the value obtained for the polymer blend III (Martins et al., in press).

\subsubsection{Moisture content (MC)}

The moisture content of the PBFs provides information on how the HE incorporation in $\kappa$-car/LBG-based blend films can affect the water sensitivity of PBFs. Table 5 shows the water content of $\kappa$ car/LBG films with different HE proportions. Results show that the addition of HE does not lead to a statistically significant difference of the water content $(p>0.05)$ values, allowing to conclude that the HE addition does not have a significant influence in the hydrophobicity of the PBFs. These values of MC are in the range of those obtained for other polysaccharide-based films (Garcia, Pinotti, \& Zaritzky, 2006).

\subsubsection{Mechanical properties - tensile strength (TS) and elongation-at-break (EB)}

The mechanical strength and extensibility (given by TS and $\mathrm{EB}$, respectively) are required for a PBF to resist external stress and maintain its integrity when applied for example, as a packaging for food products. The effect of the incorporation of HE in $\kappa$-car/LBG PBFs on the mechanical properties of the films is shown in Table 5 . The incorporation of HE in $\kappa$-car/LBG-based films leads to higher TS values $(p<0.05)$. However, no statistically significant differences $(p>0.05)$ are observed when the EB values are compared. The HE incorporation changes the TS of the PBFs, explained by the chemical modifications in the PBF. This was confirmed by FTIR analyses where is showed that the HE presence lead to some modifications in the PBFs, that can be related with the improved TS. Similar results were shown for wheat gluten based films, where the presence of a high ratio of xylan leads to the increase of TS values (Kayserilioğlu, Bakir, Yilmaz, \& Akkaş, 2003). An increase of TS has been also reported when microcrystalline cellulose was added to hydroxypropylmethylcellulose-based films (Dogan \& McHugh, 2007). The obtained values are in agreement with reported results for other polysaccharide-based films (Martins, Cerqueira, Souza, Avides, \& Vicente, 2010; Mikkonen et al., 2007).
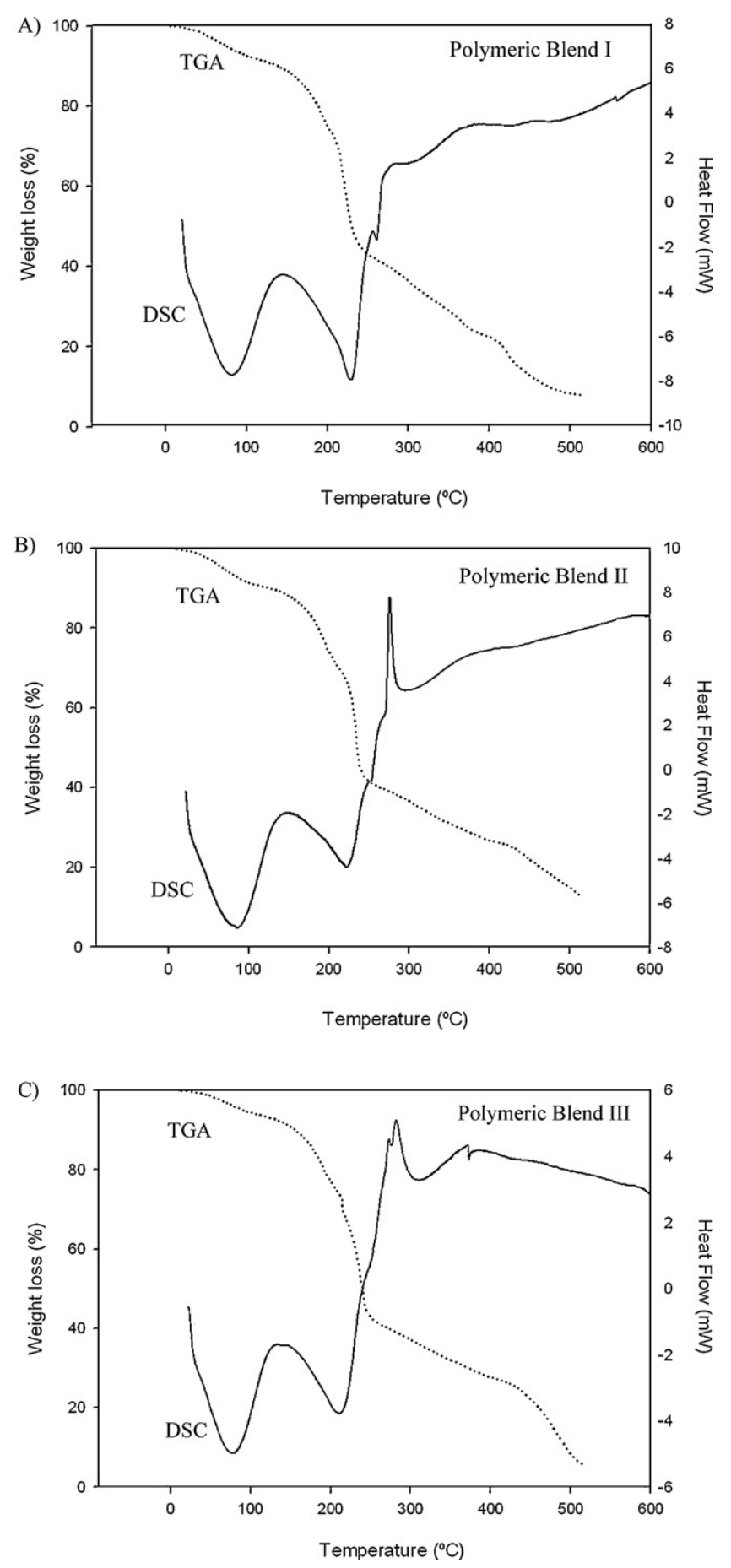

Fig. 5. Thermogravimetric and differential scanning calorimetry analyses: polymer blend film I (A); polymer blend film II (B); polymer blend film III (C).

\subsubsection{Opacity}

Opacity is a valuable property in the PBFs, indicating the capacity of the films as a barrier to light; and also can be reported as a way to relate the higher or lower miscibility of the biopolymers ( $\mathrm{Li}$, Kennedy, Jiang, \& Xie, 2006). Table 5 shows the values of the opacity for the PBFs. The presence and the increase of HE proportion in the $\kappa$-car/LBG-based films lead to an increase of the opacity of the PBFs. This increase can be related with the HE structure and the modification of the polymer blend film structure after the incorporation of HE. 


\subsubsection{Thermogravimetric analyses (TGA) and differential} scanning calorimetry (DSC)

TGA analysis showed the changes in sample weight loss with the temperature increment and was performed in order to determine the thermal stability of the PBFs. As shown in Fig. 5A-C, several events can be distinguished during the heating process of the PBFs. Martins et al. (in press) reported an similar profile for $\kappa$-car/LBG films, using the same proportions of this study (Fig. 5A). Initial weight loss was observed on the TGA curves (about $80-90^{\circ} \mathrm{C}$ ), this weight loss was the result of the evaporation of water from the PBFs (Fig. 5A-C). According to Martins et al. (2012), the behavior between 170 and $230^{\circ} \mathrm{C}$, is attributed to the presence of glycerol (plasticizer). In this work, the thermal degradation of the PBFs (Fig. $5 \mathrm{~A}-\mathrm{C}$ ) were found to start at about $160^{\circ} \mathrm{C}$, and their maximum rates of weight loss were observed between 200 and $320^{\circ} \mathrm{C}$. Beyond this temperature, thermal degradation takes place. As can be seen in Fig. $5 \mathrm{~A}-\mathrm{C}$, the behavior of the polymeric blend films I, II and III exhibited a thermal decomposition at higher temperature $\left(>320^{\circ} \mathrm{C}\right)$, which represented about $70 \%$ of the total weight loss. This indicated that interactions between $\kappa$-car/LBG/HE had been occurred. Finally, after thermal degradation slight changes in the weight of the PBFs were recorded.

DSC curves (Fig. 5A-C) of the polymeric blend films I, II and III showed an endothermic peak at 78,82 and $77^{\circ} \mathrm{C}$, respectively, which was attributed to the loss of moisture (water) and represents the energy required to vaporize water present in the PBFs. No glass transition temperature $\left(T_{g}\right)$ was recorded. The reason may be attributed to interference of the $T_{g}$ transition by the moisture endothermic peak. The PBFs start to decompose at approx. $130^{\circ} \mathrm{C}$. They decompose into various compounds as heat is gradually increased. At this point, an exothermic peak appears on the DSC curve corresponding to the decomposition of the PBFs, an endothermic peak at approx. $215^{\circ} \mathrm{C}$ is shown (Fig. 5A-C). Further, the energy liberated was observed in the exothermic peaks at 252, 274 and $282^{\circ} \mathrm{C}$ for the polymeric blend films I, II and III, resulted from the maximum decomposition of the polysaccharides, this observation may indicate that the PBF have high thermo-stability.

\section{Conclusions}

The role of an integrated biorefinery is the fractionation of compounds such as hemicellulose from LCM followed by the production of value-added products (polymer blend films used here). This concept of biorefinery has received special attention and offers a potential opportunity in the application of LCM. Autohydrolysis under selected conditions caused the selective extraction and depolymerization of hemicellulose from LCM. Moreover, the characteristics of the autohydrolysis extracted hemicellulose indicate that it is a promising material for making new renewable polymer blend films. Results showed that the incorporation of the HE under certain proportions in $\mathrm{\kappa}$-car/LBG-based films and with an appropriate plasticizer (glycerol) increased slight the barrier to water-vapor, $\mathrm{TS}$, opacity and thermal properties of $\mathrm{\kappa}$-car/LBG-based films.

\section{Acknowledgements}

The authors Héctor A. Ruiz, Miguel A. Cerqueira and Hélder D. Silva thank the Portuguese Foundation for Science and Technology (FCT, Portugal) for their fellowships (Grant Numbers: $\quad$ SFRH/BPD/77361/2011, SFRH/BPD/72753/2010 and SFRH/BD/81288/2011, respectively) and Rosa M. Rodríguez-Jasso thanks Mexican Science and Technology Council (CONACYT, Mexico) for PhD fellowship support (Grant Number: 206607/230415).

\section{References}

Akpinar, O., Erdogan, K., \& Bostanci, S. (2009). Production of xylooligosaccharides by controlled acid hydrolysis of lignocellulosic materials. Carbohydrate Research, 344, 660-666. http://dx.doi.org/10.1016/j.carres.2009.01.015

Avérous, L., \& Le Digabel, F. (2006). Properties of biocomposites based on lignocellulosic fillers. Carbohydrate Polymers, 66, 480-493. http://dx.doi.org/10.1016/j.carbpol.2006.04.004

Boussarsar, H., Rogé, B., \& Mathlouthi, M. (2009). Optimization of sugarcane bagasse conversion by hydrothermal treatment for the recovery of xylose. Bioresource Technology, 100, 6537-6542. http://dx.doi.org/10.1016/j.biortech.2009.07.019

Carvalheiro, F., Silva-Fernandes, T., Duarte, L. C., \& Gírio, F. M. (2009). Wheat straw autohydrolysis: Process optimization and products characterization. Applied Biochemistry and Biotechnology, 153, 84-93. http://dx.doi.org/10. 1007/s12010-008-8448-0

Casariego, A., Souza, B. W. S., Cerqueira, M. A., Teixeira, J. A., Cruz, L., Díaz, R., et al. (2009). Chitosan/clay films' properties as affected by biopolymer and clay micro/nanoparticles' concentrations. Food Hydrocolloids, 23, 1895-1902. http://dx.doi.org/10.1016/j.foodhyd.2009.02.007

Cerqueira, M. A., Pinheiro, A. C., Souza, B. W. S., Lima, A. M., Ribeiro, C. Miranda, C., et al. (2009). Extraction, purification and characterization of galactomannans from non-traditional sources. Carbohydrate Polymers, 75, 408-414. http://dx.doi.org/10.1016/j.carbpol.2008.07.036

Cerqueira, M. A., Souza, B. W. S., Simões, J., Teixeira, J. A., Domingues, M. R M., Coimbra, M. A., et al. (2011). Structural and thermal characterization of galactomannans from non-conventional sources. Carbohydrate Polymers, 83, 179-185. http://dx.doi.org/10.1016/j.carbpol.2010.07.036

Cherubini, F., \& Ulgiati, S. (2010). Crop residues as raw materials for biorefinery systems - A LCA case study. Applied Energy, 87, 47-57. http://dx.doi.org/10.1016/j. apenergy.2009.08.024

Dogan, N., \& McHugh, T. H. (2007). Effects of microcrystalline cellulose on functional properties of hydroxy propyl methyl cellulose microcomposite films. Journal of Food Science, 72, E16-E22. http://dx.doi.org/10.1111/j.1750-3841.2006.00237.x

Garrote, G., Domínguez, H., \& Parajó, J. C. (2002). Autohydrolysis of corncob: Study of non-isothermal operation for xylooligosaccharide production. Journal of Food Engineering, 52, 211-218. http://dx.doi.org/10.1016/S0260-8774(01)00108-X

Garcia, M. A., Pinotti, A., \& Zaritzky, N. E. (2006). Physichochemical, water vapor barrier and mechanical properties of corn starch and chitosan composite films. Starch, 58, 453-463. http://dx.doi.org/10.1002/star.200500484

Gírio, F. M., Fonseca, C., Carvalheiro, F., Duarte, L. C., Marques, S., \& Bogel-Lukasik, R. (2010). Hemicelluloses for fuel ethanol: A review. Bioresource Technology, 101, 4775-4800. http://dx.doi.org/10.1016/j.biortech.2010.01.088

González, D., Santos, V., \& Parajó, J. C. (2011). Manufacture of fibrous reinforcements for biocomposites and hemicellulosic oligomers from bamboo. Chemical Engineering Journal, 167, 278-287. http://dx.doi.org/10.1016/j.cej.2010.12.066

Hansen, N. M. L., \& Plackett, D. (2008). Sustainable films and coatings from hemicelluloses: A review. Biomacromolecules, 9, 1493-1505. http://dx.doi. org/10.1021/bm800053z

Hartman, J., Albertsson, A., Lindblad, M. S., \& Sjoberg, J. (2006). Oxygen barrier materials from renewable sources: Material properties of softwood hemicellulose-based films. Journal of Applied Polymer Science, 100, 2985-2991. http://dx.doi.org/10.1002/app.22958

http://www.fao.org/ (accessed 19.06.12)

Kayserilioğlu, B. Ş., Bakir, U., Yilmaz, L., \& Akkaş, N. (2003). Use of xylan, an agricultural by-product, in wheat gluten based biodegradable films: Mechanical, solubility and water vapor transfer rate properties. Bioresource Technology, 87, 239-246. http://dx.doi.org/10.1016/S0960-8524(02)00258-4

Kim, B., \& Day, D. F. (2011). Composition of sugar cane, energy cane, and sweet sorghum suitable for ethanol production at Louisiana sugar mills. Journal of Industrial Microbiology \& Biotechnology, 38, 803-807. http://dx.doi.org/10.1007/s10295-010-0812-8

Li, B., Kennedy, J. F., Jiang, Q. G., \& Xie, B. J. (2006). Quick dissolvable, edible and heatsealable blend films based on konjac glucomannan - Gelatin. Food Research International, 39, 544-549. http://dx.doi.org/10.1016/j.foodres.2005.10.015

Liu, Z., Fatehi, P., Sadeghi, S., \& Ni, Y.(2012). Application of hemicellulose precipitated via ethanol treatment of pre-hydrolysis liquor in high-yield pulp. Bioresource Technology, 102, 9613-9618. http://dx.doi.org/10.1016/j.biortech.2011.07.049

Makishima, S., Mizuno, M., Sato, N., Shinji, K., Suzuki, M., Nozaki, K., et al. (2009). Development of continuous flow type hydrothermal reactor for hemicellulose fraction recovery from corncob. Bioresource Technology, 100, 2842-2848. http://dx.doi.org/10.1016/j.biortech.2008.12.023

Martins, J. T., Bourbon, A. I., Pinheiro, A. C., Souza, B. W. S., Cerqueira, M. A., \& Vicente, A. A. Biocomposite films based on $\kappa$-carrageenan/locust bean gum blends and clays: Physical and antimicrobial properties. Food and Bioprocess Technology, in press

Martins, J. T., Cerqueira, M. A., Bourbon, A. I., Pinheiro, A. C., Souza, B. W. S., \& Vicente, A. A. (2012). Synergistic effects between $\kappa$-carrageenan and locust bean gum on physicochemical properties of edible films made thereof. Food Hydrocolloids, 29, 280-289. http://dx.doi.org/10.1016/j.foodhyd.2012.03.004

Martins, J. T., Cerqueira, M. A., Souza, B. W. S., Avides, M. C., \& Vicente, A A. (2010). Shelf life extension of ricotta cheese using coatings of galactomannans from nonconventional sources incorporating nisin against Listeria monocytogenes. Journal of Agricultural and Food Chemistry, 58(3), 1884-1891. http://dx.doi.org/10.1021/jf902774z

Mikkonen, K. S., Rita, H., Helén, H., Talja, R. A., Hyvönen, L., \& Tenkanen, M. (2007). Effect of polysaccharide structure on mechanical and thermal 
properties of galactomannan-based films. Biomacromolecules, 8, 3198-3205. http://dx.doi.org/10.1021/bm700538c

Mikkonen, K. S., \& Tenkanen, M. Sustainable food packaging materials based on future biorefinery products: Xylans and mannans. Trends in Food Science E Technology, in press

Miller, K. S., \& Krochta, J. M. (1997). Oxygen and aroma barrier properties of edible films: A review. Trends in Food Science and Technology, 8, 228-237. http://dx.doi.org/10.1016/S0924-2244(97)01051-0

Montané, D., Nabarlatz, Martorell, A., Torné-Fernández, V., \& Fierro, V. (2006). Removal of lignin and associated impurities from xylo-oligosaccharides by activated carbon adsorption. Industrial \& Engineering Chemistry Research, 45, 2294-2302. http://dx.doi.org/10.1021/ie051051d

Oliveira, E. E., Silva, A. E., Júnior, T. N., Gomes, M. C. S., Aguiar, L. M., Marcelino, H. R., et al. (2010). Xylan from corn cobs, a promising polymer for drug delivery: Production and characterization. Bioresource Technology, 101, 5402-5406. http://dx.doi.org/10.1016/j.biortech.2010.01.137

Overend, R. P., \& Chornet, E. (1987). Fractionation of lignocellulosics by steamaqueous pretreatments. Philosophical Transactions for the Royal Society of London A, 321, 523-536. http://dx.doi.org/10.1098/rsta.1987.0029

Peng, F., Ren, J.-L., Xu, F., Bian, J., Peng, P., \& Sun, R.-C. (2009). Comparative study of hemicelluloses obtained by graded ethanol precipitation from sugarcane bagasse. Journal of Agricultural and Food Chemistry, 57, 6305-6317. http://dx.doi.org/10.1021/jf900986b

Roos, A., Persson, T., Krawczyk, H., Zacchi, G., \& Stalbrand, H. (2009). Extraction of water-soluble hemicelluloses from barley husks. Bioresource Technology, 100, 763-769. http://dx.doi.org/10.1016/j.biortech.2008.07.022

Ruiz, H. A., Ruzene, D. S., Silva, D. P., Macieira da Silva, F. F., Vicente, A. A., \& Teixeira, J. A. (2011). Development and characterization of an environmentally friendly process sequence (autohydrolysis and organosolv) for wheat straw delignification. Applied Biochemistry and Biotechnology, 164, 629-641. http://dx.doi.org/10.1007/s12010-011-9163-9

Ruiz, H. A., Ruzene, D. S., Silva, D. P., Quintas, M. A. C., Vicente, A. A., \& Teixeira, J. A. (2011). Evaluation of a hydrothermal process for pretreatment of wheat straw-Effect of particle size and process conditions. Journal of Chemical Technology \& Biotechnology, 86, 88-94. http://dx.doi.org/10.1002/jctb.2518

Ruiz, H. A., Silva, D. P., Ruzene, D. S., Lima, F. L., Vicente, A. A., \& Teixeira, J. A. (2012) Bioethanol production from hydrothermal pretreated wheat straw by a flocculating Saccharomyces cerevisiae strain - Effect of process conditions. Fuel, 95, 528-536. http://dx.doi.org/10.1016/j.fuel.2011.10.060

Ruiz, H. A., Vicente, A. A., \& Teixeira, J. A. (2012). Kinetic modeling of enzymatic saccharification using wheat straw pretreated under autohydrolysis and organosolv process. Industrial Crops and Products, 36, 100-107. http://dx.doi.org/10. 1016/j.indcrop.2011.08.014

Sanchez-Garcia, M. D., Gimenez, E., \& Lagaron, J. M. (2008). Morphology and barrier properties of solvent cast composites of thermoplastic biopolymers and purified cellulose fibers. Carbohydrate Polymers, 71, 235-244. http://dx.doi.org/10.1016/j.carbpol.2007.05.041

Sedlmeyer, F. B. (2011). Xylan as by-product of biorefineries: Characteristics and potential use for food applications. Food Hydrocolloids, 25, 1891-1898. http://dx.doi.org/10.1016/j.foodhyd.2011.04.005

Şen, M., \& Erboz, E. N. (2010). Determination of critical gelation conditions of $\kappa-$ carrageenan by viscosimetric and FT-IR analyses. Food Research International, 43, 1361-1364. http://dx.doi.org/10.1016/j.foodres.2010.03.021

Souza, B. W. S., Cerqueira, M. A., Teixeira, J. A., \& Vicente, A. A. (2010). The use of electric fields for edible coatings and films development and production: A review. Food Engineering Reviews, 2, 244-255. http://dx.doi.org/10. 1007/s12393-010-9029-X

Sun, X.-F., Sun, R., Fowler, P., \& Baird, M. S. (2005). Extraction and characterization of original lignin and hemicelluloses from wheat straw. Journal of Agricultural and Food Chemistry, 53, 860-870. http://dx.doi.org/10.1021/jf040456q

Sun, R. C., Tomkinson, J., Wang, Y. X., \& Xiao, B. (2000). Physico-chemical and structural characterization of hemicelluloses from wheat straw by alkaline peroxide extraction. Polymer, 41, 2647-2656. http://dx.doi.org/10.1016/S0032 -3861(99)00436-X

Varghese, A. (1998). Studies on acrylonitrile butadiene rubber/poly(ethylene-co-vinyl acetate) (NBR/EVA) blends. Ph.D. Thesis. School of Chemical Sciences, Mahatma Gandhi University, Kottayam, Kerala, India.

Vicente, A. A., Cerqueira, M. A., Hilliou, L., \& Rocha, C. (2011). Protein-based resins for food packaging. In J. M. Lagaron (Ed.), Multifunctional and nanoreinforced polymers for food packaging (pp. 610-648). Cambridge, UK: Woodhead Publishing Limited.

Wanchoo, R. K., \& Sharma, P. K. (2003). Viscometric study on the compatibility of some water-soluble polymer-polymer mixtures. European Polymer Journal, 39, 1481-1490. http://dx.doi.org/10.1016/S0014-3057(02)00386-5

Xu, X., Li, B., Kennedy, J. F., Xie, B. J., \& Huang, M. (2007). Characterization of konjac glucomannan-gellan gum blend films and their suitability for release of nisin incorporated therein. Carbohydrate Polymers, 70, 192-197. http://dx.doi.org/10.1016/j.carbpol.2007.03.017

Yoshida, T., Tsubaki, S., Teramoto, Y., \& Azuma, J.-i. (2010). Optimization of microwave-assisted extraction of carbohydrates from industrial waste of corn starch production using response surface methodology. Bioresource Technology, 101, 7820-7826. http://dx.doi.org/10.1016/j.biortech.2010.05.011

Yu, L., Dean, K., \& Li, L. (2006). Polymer blends and composites from renewable resources. Progress in Polymer Science, 31, 576-602. http://dx.doi.org/10.1016/j.progpolymsci.2006.03.002

Zou, Y., Chen, X., Yang, W., \& Liu, S. (2011). Response surface methodology for optimization of the ultrasonic extraction of polysaccharides from Codonopsis pilosula Nannf.var.modesta L.T.Shen. Carbohydrate Polymers, 84, 503-508. http://dx.doi.org/10.1016/j.carbpol.2010.12.013 